\title{
Insufficiency fracture of the unresurfaced patella following total knee arthroplasty
}

\author{
Alexander Schuh ${ }^{1 *}$, Ralph Schuh ${ }^{2}$, Albert Fujak ${ }^{3}$, Wolfgang Hönle ${ }^{1}$ and Sandeep Kashyap ${ }^{4}$ \\ ${ }^{1}$ Musculoskeletal Center, Neumarkt Hospital, 92318 Neumarkt, Germany \\ ${ }^{2}$ Orth.Med Weiden, 92637 Weiden, Germany \\ ${ }^{3}$ Department of Orthopaedics, University of Erlangen- Nurenberg, Erlangen, Germany \\ ${ }^{4}$ Postgraduate Institute of Medical Education \& Research, Chandigarh, India
}

\begin{abstract}
Atraumatic patellar fractures after Total Knee Arthroplasty (TKA) are rare in unresurfaced patella. Previous reports are few and have highlighted association of these fractures with rheumatoid arthritis and gout along with interference with patellar blood flow after lateral release and Hoffas' fat pad excision. We report a case of insufficiency fracture of patella in a patient following TKA after post-operative haematoma and arthrofibrosis that was managed conservatively.
\end{abstract}

\section{Introduction}

Patellar fractures after Total Knee Arthroplasty (TKA) occur in 0.2 and $21 \%$ of patients undergoing patellar resurfacing [1]. However patellar fractures without replacement of patellar component are rare and occur in only $0.05 \%$ patients $[2,3]$. Medial parapatellar arthrotomy combined with lateral release and excision of Hoffas' fat pad compromise the patellar blood supply by division of geniculate and infrapatellar arteries [4,5] and this factor has usually been ascribed to causing devascularisation of patella and pathological fracture. Contributing factors include mainly rheumatoid arthritis, corticosteroid intake, gout, excessive knee flexion, obesity, age more than 60 years and these are the main causes in previously reported cases [2]. However patellar fracture without resurfacing is rare in osteoarthritis. We describe a Case with patellar fracture without resurfacing and without any trauma after TKA due to post-operative arthrofibrosis.

\section{Case report}

In February 2010 we performed hybrid total knee arthroplasty (TKA) in a 66-year-old woman due to severe osteoarthritis of the right knee (Figure 1). No patellar resurfacing was done, but careful lateral release was done to protect lateral geniculate artery. Preoperative range of motion was extension / flexion $0 / 5 / 90^{\circ}$. One week later we performed open revision due to deep haematoma. Intraoperative samples were sterile with no signs of infection. Further follow- up was uneventful. The patient was recommended to use 2 crutches with partial weight bearing of $20 \mathrm{~kg}$ for 6 weeks. The patient received intensive physiotherapy. Nevertheless, the maximum postoperative range of motion was $0 / 0 / 90^{\circ}$. X ray taken after 1 week showed the status after TKR with correct position of the femoral and tibial component (Figure 2). The patient did not wish further revision due to arthrofibrosis. 1.5 years later we saw the patient again for regular clinical and radiologic follow- up. The patient was out of any complaints. Range of motion was $0 / 0 / 90^{\circ}$. The patient was able to raise her leg even against strong resistance. X-ray of the right knee showed a correct position of the femoral and tibial component with no radiolucencies but lengthening of the patella with multiple fragments compatible to an insufficiency fracture of the patella (Figure 3). As the patient had a good function of the knee especially of the extensor mechanism we recommended conservative treatment with regular clinical and radiologic follow-ups.

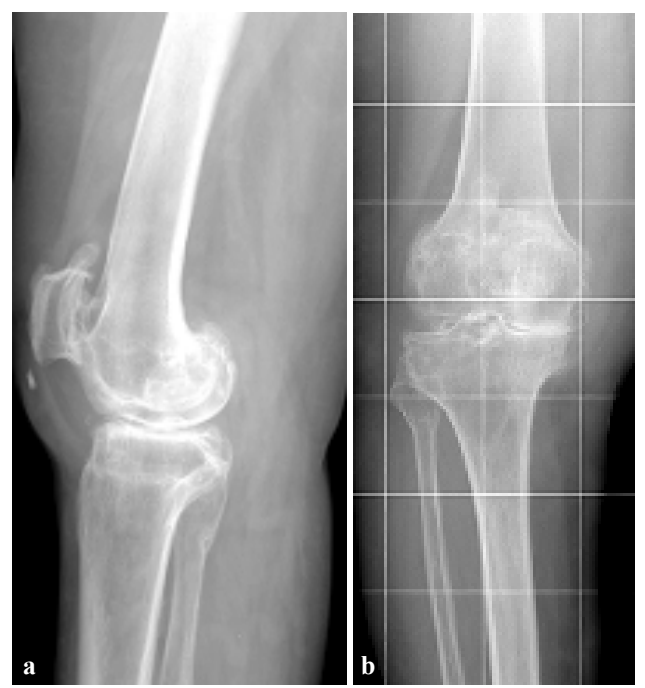

Figure 1. X ray of the right knee ap view a. and lateral view; b. shows to severe osteoarthritis of the right knee with a varus leg axis.

Correspondence to: Dr.med.habil.Alexander Schuh, Head of Musculoskeletal Center, Neumarkt Hospital, Teaching Hospital of the University of ErlangenNurenberg, Nürnberger Str. 1292318 Neumarkt i.d. Opf, Germany, Tel: +499181-420-3500; Fax: +49-9181-420-3503; E-mail: Alexander.Schuh@klinikum. neumarkt.de

Key words: insufficiency fracture, unresurfaced, patella, total knee arthroplasty (TKA)

Received: February 06, 2018; Accepted: February 23, 2018; Published: February 28,2018 

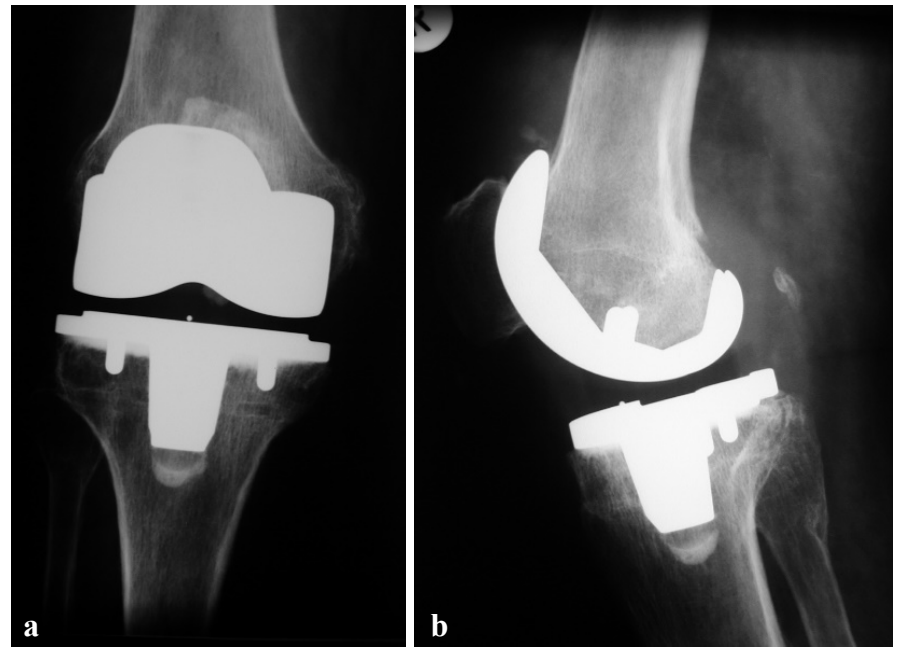

Figure 2. $\mathrm{X}$ ray of the right knee ap view a. and lateral view; b. shows TKA with a correct position of the femoral and tibial component.
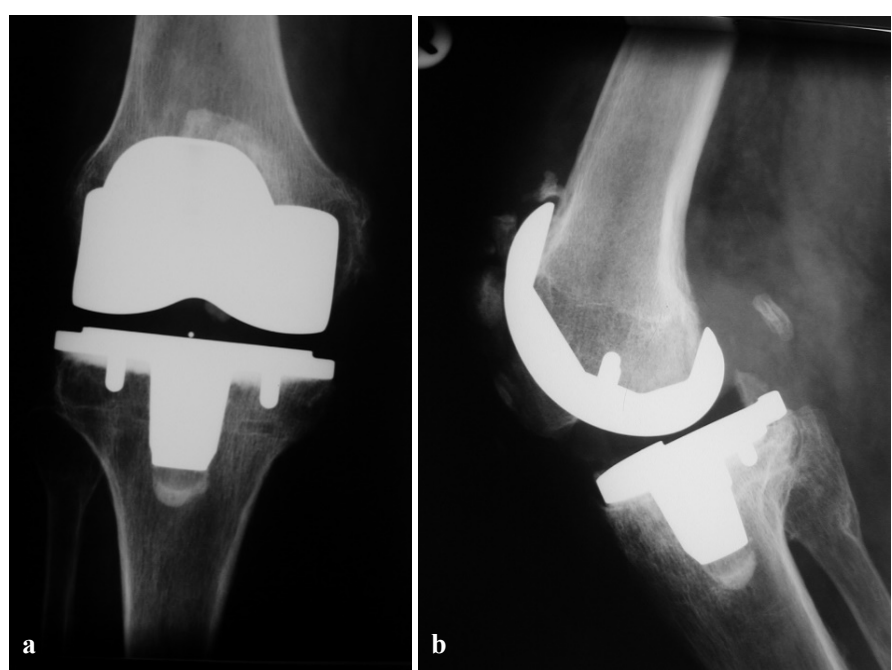

Figure 3. $\mathrm{X}$ ray of the right knee ap view $\mathrm{a}$. and lateral view; b. reveals a correct position of the femoral and tibial component with no radiolucencies but lengthening of the patella with multiple fragments compatible to an insufficiency fracture of the patella.

\section{Discussion}

Anterior knee pain and patellar fracture are significant complications following Total Knee Arthroplasty (TKA). Patellar fractures without trauma are rare in unresurfaced patella following TKA. Disruption of blood supply has been one of the important reasons causing devascularisation of patella, nevertheless some studies suggest routine patellar resurfacing $[1,3,6]$. However, the complications increase manifold with resurfacing which can be due to incorrect patellar tracking, metal component, uncemented component and patellar clunk syndrome; that too can cause fracture of patella or patellofemoral problems after TKA the percentage of which is quite high [1]. It is noteworthy to mention that involvement of extensor mechanism is the most common complication after TKA [1,7].

In a recent study of finite element models analysis of strain pattern of patellofemoral (PF) joint in the natural and implanted knee, the volume of bone experiencing strains $>0.5 \%$ in the implanted condition was approximately $200 \%$ larger, on average, than the natural condition. It was also found that highly strained bone was evenly distributed between medial and lateral regions in the natural knee whereas the implanted specimens demonstrated significantly larger volumes of highly strained bone medially as a result of substantially lower modulus bone in the medial compartment. This points to high stress and strain in patella after TKA that predisposes it to insufficiency fracture [8].

Previous case reports accused RA as the most common cause of fracture of the patella and majority of these patients had steroid intake that contributed to Osteonecrosis $[9,10]$. Reed et al. [2] described a patellar stress fracture as a complication of knee joint arthroplasty without patellar resurfacing. In this case the patient suffered from gout and a previously avascular necrosis of the talus. In that way Reed et al. [2]. blamed gout in combination with lateral release as the underlying condition of patellar stress fracture. Our case is different with no underlying metabolic disease but arthrofibrosis. We performed carefully lateral release sparing lateral geniculate artery. In that way we are sure that lateral release did not compromise blood supply of the patella. Fracture of patella was detected 1.5 years after TKA. Fracture of the patella occurred within 2 months in the case reported by Reed $e t$ al. [2] and less than 3 years in the cases reported by Seijas Roberto et al. [7]. Ortiguera et al. [11] described that about $80 \%$ of patellar fractures occur within 3 years.

Parvizi J et al. [1] described most of the patellar fracture after TKA as asymptomatic; treatment is conservative in most cases which was similar in our case. Despite patellar fracture our patient was asymptomatic with no quadriceps weakness but limited range of motion; the fracture was detected only on routine follow- up. The probable reason for missing weakness of the extensor mechanism despite of the patella stress fracture with lengthening of the patella could be intact patellar retinacula that maintained the quadriceps function [12]. Hence conservative treatment is recommended in such insufficiency fractures of patella with good functional results. As the strain on patella after TKA is quite high, we think that lateral release of patellar retinaculum should be performed very judiciously in unsurfaced patella and care should be taken to avoid the division of lateral superior genicular artery.

\section{Conclusion}

In our case insufficiency fracture occurred due to arthrofibroses following TKA with a maximum flexion of $90^{\circ}$. In cases of asymptomatic fractures of the patella with good function of the extensor mechanism we recommend conservative treatment.

\section{References}

1. Parvizi J, Kim KI, Oliashirazi A, Ong A, Sharkey PF (2006) Periprosthetic patellar fractures. Clin Orthop Relat Res 446: 161-166. [Crossref]

2. Reed MR, Farhan MJ, Chaudhuri C (1999) Patellar stress fracture: a complication of knee joint arthroplasty without patellar resurfacing. J Arthroplasty 14: 383-385. [Crossref]

3. Deshmukh RG, Noble J (1999) An unusual complication affecting an unresurfaced patella after total knee arthroplasty. J Arthroplasty 14:895-897. [Crossref]

4. Scuderi G, Scharf SC, Meltzer LP, Scott WN (1987) The relationship of lateral releases to patella viability in total knee arthroplasty. J Arthroplasty 2: 209-214. [Crossref]

5. Scapinelli R (1967) Blood supply of the human patella. Its relation to ischaemic necrosis after fracture. J Bone Joint Surg Br 49: 563-570. [Crossref]

6. Kayler DE, Lyttle D (1988) Surgical interruption of patellar blood supply by total knee arthroplasty. Clin Orthop Relat Res: 221-227. [Crossref]

7. Seijas R, Orduna JM, Castro MC, Granados N, Baliarda J, et al. (2009) Fracture of the unresurfaced patella after total knee arthroplasty: a report of two cases. J Orthop Res 17: 251-254. [Crossref]

8. Fitzpatrick CK, Baldwin MA, Ali AA, Laz PJ, Rullkoetter PJ (2011) Comparison of patellar bone strain in the natural and implanted knee during simulated deep flexion. $J$ Orthop Res 29: 232-239. [Crossref] 
9. Grace JN, Sim FH (1988) Fracture of the patella after total knee arthroplasty. Clin Orthop Relat Res: 168-175. [Crossref]

10. Freeman MA, hammer A (1978) Patellar fractureafter replacement of tibio-femoral joint with the ICLH prosthesis. Arch Orthop Trauma Surg 92: 63-67. [Crossref]
11. Ortiguera CJ, Berry DJ (2002) Patellar fracture after total knee arthroplasty. $J$ Bone Joint Surg Am 84-A: 532-540. [Crossref]

12. Smillie IS (1980): The function of patella. In: Diseases of the knee joint. 2ed.Churchil Living stone, Edinburgh.

Copyright: $(02018$ Schuh A. This is an open-access article distributed under the terms of the Creative Commons Attribution License, which permits unrestricted use, distribution, and reproduction in any medium, provided the original author and source are credited. 